\title{
A Rare Case of Fetal Hydrothorax treated through Amniocentesis and Thoracentesis
}

\author{
Dinu-Florin Albu ${ }^{1}$, Cristina-Crenguta Albu${ }^{2}$, Stefan-Dimitrie Albu ${ }^{3}$, Mihai Dumitrescu ${ }^{4}$ \\ ${ }^{1}$ Dr. Dinu-Florin Albu, MD, PhD, Associate Professor, Obstetrics \& Gynecology and Medical Genetics, Expert in Maternal- \\ Fetal Ultrasound and Maternal-Fetal Medicine, ${ }^{2}$ Dr. Cristina-Crenguta Albu, MD, PhD, Associate Professor, \\ Ophthalmology and Medical Genetics, ${ }^{3}$ Stefan-Dimitrie Albu, Medical Student, ${ }^{4}$ Mihai Dumitrescu, MD, PhD Student, \\ Thoracic Surgery and Medical Genetics. All are affiliated with University of Medicine and Pharmacy Carol Davila, \\ Bucharest, Romania and Alco San Clinic, Maternal-Fetal Medicine Dept, Bucharest, Romania
}

Address for correspondence: Dr. Cristina-Crenguta Albu, E-mail: stevealbu@yahoo.com, 27A, Catedrei Street, 1st District, 014162, Bucharest, Romania

\begin{abstract}
We present the rare case of a 27-year-old Caucasian female which was admitted in our service at 27 weeks of gestation after beig discovered with left fetal hydrothorax during routine prenatal ultrasound. Samples of maternal blood and amniotic fluid (trough amniocentesis) were obtained in order to establish the cause (immune or non-immune) and fetal thoracentesis was performed in order to allow for lung re-expansion. Analysis of the amniotic and pleural fluids trough QF-PCR and amniocyte cultures established the diagnosis of Down syndrome and the decision was taken to perform cesarean section at 33 weeks of gestation following two weeks treatment with dexamethasone.
\end{abstract}

Key words: Hydrothorax, Amniocentesis, Thoracentesis, Down Syndrome

\section{Introduction}

Fetal hydrothorax refers to a collection of fluid within the left fetal thoracic cavity as a result of leakage or generalized fluid retention from a variety of causes which can be organized into one of the following diagnostic categories: cardiovascular (21.7\%), idiopathic (17.8\%), hematologic $(10.4 \%)$, syndromic $(4.4 \%)$, chromosomal (13.4\%), lymphatic dysplasia (5.7\%), infections (6.7\%), thoracic $(6 \%)$ and others (urinary tract alformations, extra-thoracic tumors, placental, gastrointestinal) [1]. The condition mandates urgent referral to a maternal fetal medicine specialist for extensive testing because some situations must be considered prenatal emergencies after 18 weeks and one should not wait for complete results before initiating minimally invasive diagnostic procedures and treatment [2].

\section{Case Report}

A 27-year-old Caucasian female, pregnant for the first time, with negative triple test (AFP, uE3, hCG), was

Manuscript received: $24^{\text {th }}$ Nov 2014

Reviewed: $6^{\text {th }}$ Dec 2014

Author Corrected; $17^{\text {th }}$ Dec 2014

Accepted for Publication: $28^{\text {th }}$ Dec 2014 referred at 27 weeks' gestation for a routine prenatal ultrasound. The couple had normal general health and was not consanguineous and there was no family history of genetic disorders.

Routine ultrasonography revealed normal amniotic fluid measurements and a single fetus with a large hydrothorax $(\sim 200 \mathrm{ccm})$ colapsing the left lung and pushing down the driaphragm (Fig. 1). Investigations for determining the cause (non-immune or immune) of the hydrothorax were carried out and amniocentesis, followed by thoracentesis, were performed.

From the maternal blood acute phase titers were checked for syphilis, rubella parvovirus, tohoplasmosis, cytomegalovirus, rubella and antibody screening thorough indirect Coombs was performed.

The amniotic fluid (sample of 40ml) was tested for possible infection with parvovirus B19, toxoplasma, cytomegalovirus by use of PCR, while amniocyte cultures and QF-PCR were conducted in order to detect a possible genetic disorders. 


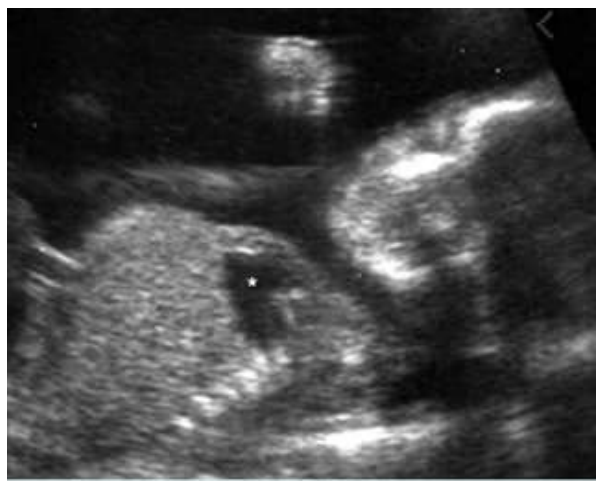

Fig 1: 2D ultrasound showing 27 weeks fetus with hydrothorax

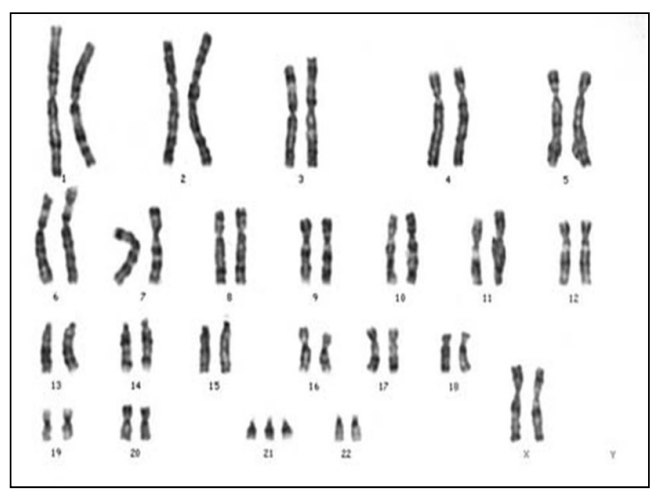

Fig. 2: Karyotype obtained from amniocyte culture showing Trisomy 21

For thoracentesis we used the same sampling kit used for amniocentesis and a sample of $70 \mathrm{ccm}$ pleural fluid was obtained at 28 weeks of gestation by using ultrasound guidance. Post procedural ultrasound examination revealed positive lung expansion.

Karyotype and QF-PCR from both amniotic fluid and thoracic fluid indicated the presence of Trisomy 21 (Fig. 2) and the decision was taken to perform a cesarean section at 33 weeks of gestation following a two weeks treatment with dexamethasone. Postoperative period was uneventfull and the newborn developed normally, weekly ultrasound examinations showing decreasingly amounts of pleural fluid with complete resorbtion observed at 8 weeks after birth.

\section{Discussion}

Despite extensive investigations, the etiology of fetal hydrothorax remains unknown in $15 \%$ to $25 \%$ of patients $[3,4]$ while chromosomal abnormalities are the cause of fetal hydrothorax in $25 \%$ to $70 \%$ of cases [5]. Standard fetal chromosome analysis is indicated in all cases of fetal hydrothorax and early referral to a maternal-fetal specialist allows for detailed and comprehensive ultrasound examination and the early identification of any treatable causes [6]. A careful search for structural fetal anomalies or genetic syndromes, signs of fetal infection, and evidence of umbilical cord or placental anomalies may rapidly indicate the cause of fetal hydrothorax while fetal karyotyping and genetic microarray molecular testing should be conducted in all cases of unexplained hydrothorax. Cytogenetic laboratories can provide a fast but limited results within 24 to 48 hours by using QF-PCR (amniotic fluid) or more detailed results by karyotyping (amniotic fluid, fetal blood). Also, amniotic fluid should also be obtained for viral and bacterial cultures, viral PCR tests, and karyotyping [7].
Although cases of spontaneous resolution have been cited for fetal hydrothorax [8,9], we took the decision to perform amniocentesis with thoracentesis since the perinatal mortality of untreated fetal hydrothorax is still high [10] and some others have reported complete resolution after single thoracentesis $[11,12,13]$.

\section{Conclusions}

Even though the use of prenatal techniques (amniocentesis) for the treatment of fetal hydrothorax is still debatable with different authors reporting higher survival rates for either the conservative management [9] or the prenatal interventions $[13,14,15]$, we do advocate that each case of fetal hydrothorax should be investigated for genetic disorders by use of minimally invasive techniques such as chorionic villus sampling or amniocentesis and that improved access to specialized maternal-fetal medicine centers for fetal evaluation and treatment can improve outcome.

\section{References}

1. Braun T, Brauer M, Fuchs I, Czernik C, Dudenhausen JW, Henrich W, et al, Mirror syndrome: a systematic review of fetal associated conditions, maternal presentation and perinatal outcome, Fetal Diagn Ther. 2010;27(4):191-203. doi: 10.1159/000305096.

\section{Désilets V, Audibert F; Society of Obstetrician and} Gynaecologists of Canada, Investigation and management of non-immune fetal hydrops, J Obstet Gynaecol Can, 2013, 35(10):923-38. 
3. Bellini C, Hennekam RC, Bonioli E, A diagnostic flow chart for non-immune hydrops fetalis, Am J Med Genet A. 2009 May;149A(5):852-3.

4. Santo S, Mansour S, Thilaganathan B, Homfray T, Papageorghiou A, Calvert S, et al, Prenatal diagnosis of non-immune hydrops fetalis: what do we tell the parents, Prenat Diagn, 2011, 31:186-195.

5. Jauniaux E, Van Maldergem L, De Munter C, Moscoso G, Gillerot Y, Nonimmune hydrops fetalis associated with genetic abnormalities, Obstet Gynecol, 1990, 75:568-572.

6. Hansen T, Non immune hydrops fetalis, In: Rudolph A, Kamei R, Overby K (eds). Rudolph's pediatrics. 21st ed., McGraw-Hill, New York, 2003.

7. Ramsay SL, Maire I, Bindloss C, Fuller M, Whitfield PD, Piraud M, et al, Determination of oligosaccharides and glycolipids in amniotic fluid by electrospray ionisation tandem mass spectrometry: in utero indicators of lysosomal storage diseases, Mol Gene Metab 2004, 83:231-238.

8. Weber AM, Philipson EH, Ingardia CJ, Spontaneous resolution of second trimester fetal pleural effusion,J Matern Fetal Neonatal Med, 1992, 1(2):87-89.

9. Klam S, Bigras JL, Hudon L, Predicting outcome in primary fetal hydrothorax, Fetal Diagn Ther, 2005, 20(5):366-370.

10. Yinon Y, Kely E, Ryan G, Fetal pleural effusions, Best Pract Res Clin Obstet Gynaecol, 2008, 22(1):77-96.

11. Hidaka N, Chiba Y, fetal hydrothorax resolving completely aftera single thoracentesis: a report of 2 cases, J Reprod Med, 2007, 52(9):843-848.

12. Alkazaleh F, Saleem M, Badran E, Intrathoracic displacement of pleuroamniotic shunt after successful in utero treatment of fetal hydrops secondary to hydrothorax. Case report and review of the literature, Fetal Diagn Ther, 2009, 25(1):40-43.

13. Derderian SC, Trivedi S, Farrell J, Keller RL, Rand $\mathrm{L}$, et al, Outcomes of fetal intervention for primary hydrothorax, J Pediatr Surg, 2014, 49(6):900903.

14. Petersen S, Kaur R, Thomas JT, Cincotta R, Gardener G. The outcome of isolated primary fetal hydrothorax: a 10-year review from a tertiary center, Fetal Diagn Ther., 2013, 34(2):69-76.

15. Albu D, Dumitrescu M, Albu C, Severin E. Fetal hydrotorax, Presented at the 61th Annual Meeting of The American Society of Human Genetics, Oct. 11 - 15, 2011, Montreal, Canada

\section{How to cite this article?}

Dinu-Florin Albu, Cristina-Crenguta Albu, Stefan-Dimitrie Albu, Mihai Dumitrescu. A Rare Case of Fetal Hydrothorax treated through Amniocentesis and Thoracentesis. Int J Med Res Rev 2015;3(1):118-120. doi:10.17511/ijmrr.2015.i1.20 